\title{
ferfings $\mathfrak{w}_{\mathfrak{c}}$ ket.
}

Behnter Band.

$\mathbb{S} \mathfrak{t} \mathfrak{u} \mathfrak{t} \mathfrak{\mathfrak { g }} \mathfrak{a} \mathfrak{\mathfrak { t }} \mathbf{t}$

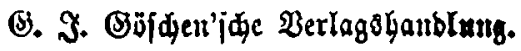

1874. 


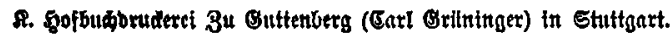

